DOI: $10.32604 /$ EE.2022.015485

\title{
ARTICLE
}

\section{Discount Rate of China's New Energy Power Industry}

\author{
Yafei Rong ${ }^{1}$ and Xudong Sun ${ }^{1,2, *}$ \\ ${ }^{1}$ School of Management, China University of Mining and Technology (Beijing), Beijing, 100083, China \\ ${ }^{2}$ State Key Laboratory of Coal Resources and Safe Mining, China University of Mining and Technology (Beijing), Beijing, \\ 100083, China \\ *Corresponding Author: Xudong Sun. Email: sunxudong@cumtb.edu.cn
}

Received: 21 December 2020 Accepted: 27 April 2021

\begin{abstract}
Under the dual pressures of energy crisis and environmental pollution, China's new energy power industry has become a focal point for environmental management and requires greater investment. In this context, as a significant input of investment projects, discount rate requires a well-calibrated evaluation because new energy power investment projects are highly capital intensive. The main objective of this paper is to evaluate the discount rate of China's new energy power industry. First, we use Moving Average to correct the parameters of capital asset pricing model (CAPM) and weighted average cost of capital, which extends the literature on the avoidance of CAPM noise information problem. Second, we study the industry-level annual discount rates of mainly China's new energy power industries, including hydropower, nuclear power, wind power, and photovoltaic power industries for the period of 2014-2019. The results show that discount rates in China's new energy power industries evolved differently between the years of 2014-2019 with average annual discount rates being 7.56\%, 5.83\%, $5.60 \%$, and $8.64 \%$, for the hydropower, nuclear power, wind power, and photovoltaic power industries, respectively. In 2019, the four annual discount rates were highest for the photovoltaic power industry (8.66\%), followed by hydropower $(7.17 \%)$, wind power $(5.72 \%)$, and nuclear power industry $(5.26 \%)$. Forecasting to 2020 from the 2019 evaluation base period, the discount rates are $6.37 \%, 5.00 \%, 6.57 \%$, and $9.05 \%$ for the photovoltaic power, hydropower, wind power, and nuclear power industries, respectively. Under the different capital structures, their forecasts for the photovoltaic power, hydropower, wind power, and nuclear power industries in 2020 are, respectively, within [4.35\%, 9.24\%], [3.92\%, 7.10\%], [4.58\%, 10.40\%], [5.46\%, 14.81\%]. We also discussed more details on capital structure and forecast period of discount rates for China's new energy power industries. Our analysis shows that it is necessary to establish a new energy power industry database and steadily promote the implementation of policies.
\end{abstract}

\section{KEYWORDS}

Discount rate; China's new energy power industry; moving average; capital asset price model; weighted average cost of capital

\section{Introduction}

Under the dual pressures of energy crisis and environmental pollution, China has taken the path of green and low carburizable development through deepening reform of the electrical power industry. In this context, China substantially increases the share of new energy sources to meet the energy demand in the future.

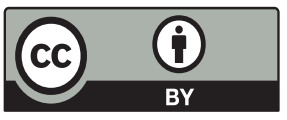

This work is licensed under a Creative Commons Attribution 4.0 International License, which permits unrestricted use, distribution, and reproduction in any medium, provided the original work is properly cited. 
Increases in energy sources are mainly in hydropower resources, nuclear power resources, wind power resources, and photovoltaic power resources. For example, the proportion of new energy power installed capacity has rapidly increased from 32.6\% in 2014 to $40.8 \%$ in 2019 (Fig. 1). Because the expansion of China's new energy power industry requires large investment, and the deploying new energy power investment project requires large up-front investments, the discount rate is highly sensitive for new energy power investment projects and requires well-calibrated evaluation [1-3]. Discount rate as the expected rate of return determines whether a project passes the cost-benefit test [4]. If regulators want to mimic workable competition and regulate investor behavior, the investors should be allowed to earn returns in excess of their discount rate [5]. However, the latest release data of China's new power industry discount rates was in 2016. Discount rates of the hydropower and photovoltaic power industries were issued in 2006 by Ministry of Construction Marks Quota Research Institute, and discount rates for the nuclear power industry were in 2009 and the wind power industry in 2016 by the National Energy Administration. Discount rates changed over time [6-11] for several reasons including changes of policies [7-9], technologies innovation [10-12], and financial factors [11]. It is well known that the social, economic, market, policy, technology, and other factors that affect the discount rate of China's new energy power industry are changing. So, it is necessary to update the industry-level discount rate of China's new energy power industry.
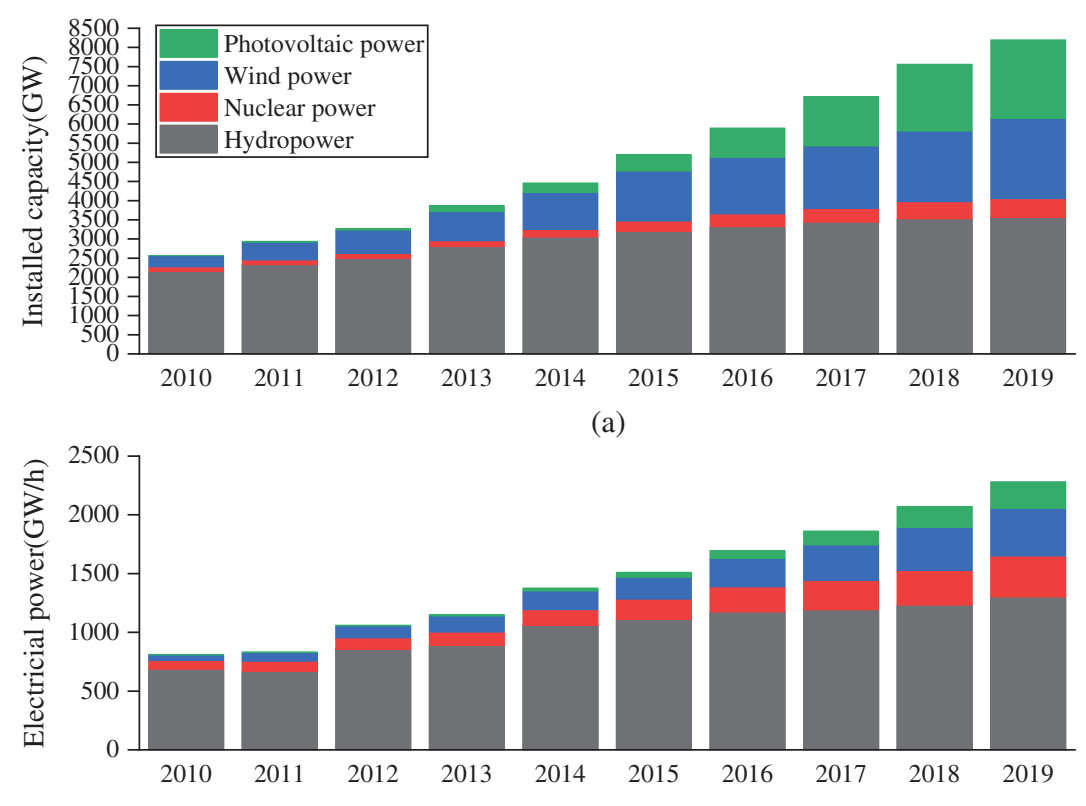

(b)

Figure 1: Installed capacity and electrical power of China's new energy power industry in which the data is from National Bureau of Statistics of China. (a) installed capacity, (b) electrical power

The methods for calculating the discount rate have been the typical project simulation method, the Delphi method, the capital asset pricing model (CAPM), and the weighted average cost of capital (WACC). The typical project simulation method takes the actual project as the background, and it simulates and calculates the parameters of the project by effectively obtaining information about similar projects. The Delphi method needs multiple rounds of anonymous consultation and modification of expert opinions on questions raised in the questionnaire. Consistent opinions of experts will be used for the calculation. The CAPM model divides the cost of a company's own capitals into two parts: the risk-free rate and the expected risk reward of its own capitals, which are used to calculate the cost of capital. The 
WACC model divides the capital of a company into two parts: cost of capital and cost of debt, which are then used to calculate the average value of the cost of obtaining investment project funds through various channels. Because the typical project simulation method is limited by the real calculated project, the method results in a large workload. The Delphi method has a complex process and strong subjective interpretation. The CAPM model does not consider the cost of debt incurred by project financing. The WACC is an appropriate tool for assessing investment risk and efficiently capturing the real discount rate of investments that have been identified in the literature [2,13-16].

WACC can go back to Miles et al. [17] in 1980, which consisted of the cost of debt and cost of equity. As firms with a high cost of debt invest less, most research focuses on the impact of the cost of equity [18]. Some authors proposed that the return on equity capital investment calculated by CAPM can be as the cost of equity of the WACC model [13-15,19]. For example, Inmaculada et al. [13] discussed discount rates of the solar photovoltaic plants of Spain with CAPM as the component of WACC. Angelopoulos et al. [14] studied the most important risk categories of onshore wind energy investments in 28 countries of the European Union and applied the CAPM and WACC methods. Markauskas et al. [15] compared the discount rates for different subdivision industries of the Lithuanian manufacturing sector with CAPM and WACC. Vergara et al. [20] used CAPM and WACC methods to evaluate the discount rate for highway concessionaires in Chile. However, random noise information of statistical information caused inaccurate CAPM-based results of discount rate with expected returns differing from actual returns [18,21,22]. Some authors propose implied costs using capital models such as Gordon's wealth growth model [18,23], or the residual income model [18] to avoid the random noise information of statistical information. A few authors directly consider the noise information of the statistical information on CAPM; for example, Chrysafis [24] used the fuzzy set theory to propose a possibilistic CAPM to avoid biased statistical information or historical data. However, the possibilistic CAPM is more applicable to individual or several projects at the company level. For a large number of projects at the company level, industry sector, or city sector, it has a complex process and strong subjective interpretation. Thus, studying the noise in the statistical information on CAPM is still a lack when calculating the cost of equity.

It is necessary to evaluate and update the industry-level discount rate of China's new energy power industry because China is expanding new energy power industry investment. So, we study the discount rates of mainly China's new energy power industries including hydropower, nuclear power, wind power, and photovoltaic power industries. Based on existing research for calculating discount rate, WACC is a useful tool for evaluating discount rates in which CAPM is used as the cost of equity of the WACC model. Considering the adverse effects of noise related to CAPM statistical information, the moving average (MA) method may reduce the effect of temporary variation and noise in data and improve the forecasting accuracy [25]. We attempt to use the MA method to correct the CAPM-based results of discount rate. The proposed method provides a new way to remove the effects of noise in statistical information and enriches the CAPM-based results of discount rate.

The remainder of the paper is organized as follows. Section 2 indicates the proposed method with CAPM and WACC corrected based on MA, and the data source of China's new energy power industry. Section 3 presents the calculation, analysis, and discussion of discount rate in China's new energy power industry. Section 4 presents the conclusion.

\section{Method and Data Source}

\subsection{Method}

In this section, a series of relevant algorithms are introduced. First, considering the limitation of the current CAPM and WACC on evaluation of the discount rate, we use the MA method to remove the noise from statistical data and to correct the parameters of CAPM and WACC (hereafter referred to as 
MA-CAPM-WACC). Then, we use the mean square error (MSE) to analyze the rationality and effectivity of the calculation results. The specific process is shown in Fig. 2.

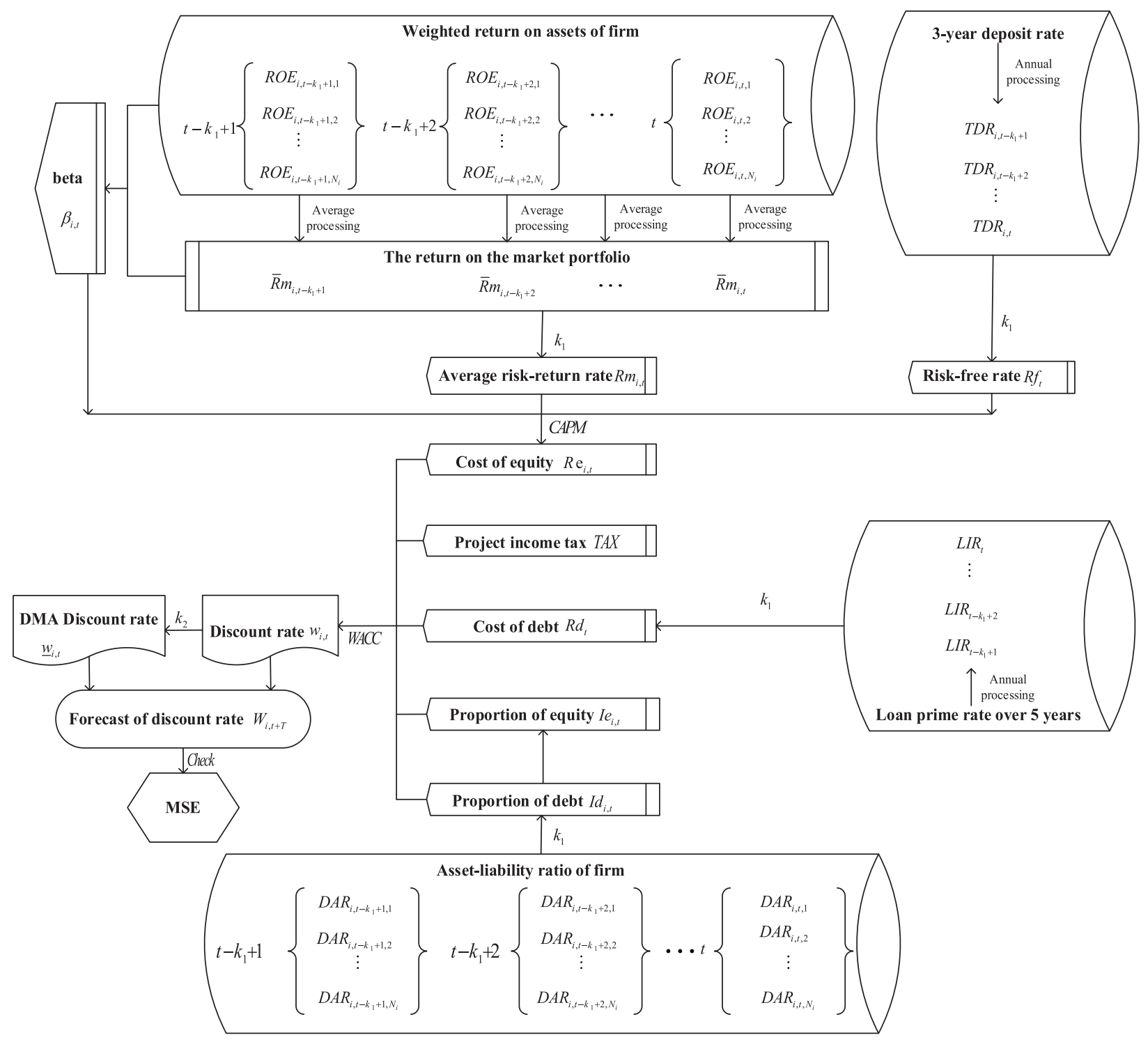

Figure 2: The calculation process of the MA-CAPM-WACC

Beta changes through time, which can be given by a covariance of returns on a particular stock and market portfolio [26]. However, the current method of beta usually is at the firm level, which is different from our study. Refer to the discount rate evaluation method at the industry level in Methods and Parameters of Economic Evaluation of Construction Projects (Third Edition) published by China's National Development and Reform Commission and the Ministry of Construction that taking the average discount rates of representative firms as the industry-level discount rate. We use the average betas of representative enterprises as the industry beta value. First, we take the main business as the initial selection criteria; specifically, a company whose main business belongs to the evaluated industry will be chosen as a sample. Second, a firm's beta should be related to firm characteristics such as firm size, 
volatility of earnings, and operational book-to-market ratio [27]. Based on data availability and company characteristics, we consider whether a company is listed as a proxy variable of company size. The listed companies, selected as samples, were those whose main business belonged to the evaluated industry. We use MA to correct the beta and remove the noise in statistical data. The beta is defined as

$$
\begin{aligned}
\beta_{i, t} & =\frac{1}{k_{i}} \sum_{\lambda=t-k_{1}+1}^{t} \beta_{i, \lambda} \\
& =\frac{1}{k_{i}} \sum_{\lambda=t-k_{1}+1}^{t} \frac{\sum_{j=1}^{N_{i}} \frac{\operatorname{cov}\left(\bar{R} m_{i, T}, R O E_{i, T, j}\right)}{\sigma^{2}\left(\bar{R} m_{i, T}\right)}}{N_{i}}
\end{aligned}
$$

where $k_{1}$ is the first step size of the MA; $T$ is the calculated interval of the beta, $T=\left\{t-2 k_{1}+2, t-2 k_{1}+3, \cdots, t-k_{1}+1\right\} ; \quad \bar{R} m_{i, T}=\left\{\bar{R} m_{i, t-2 k_{1}+2}, \bar{R} m_{i, t-2 k_{1}+3}, \cdots, \bar{R} m_{i, t-k_{1}+1}\right\}$ is the expected yield of the market investment portfolio in industry $i$ at the time of $t-2 k_{1}+2 \sim t-k_{1}+1$, $\bar{R} m_{i, t}=\frac{\sum_{j=1}^{N_{i}} R O E_{i, t, j}}{N_{i}} ; R O E_{i, T, j}=\left\{R O E_{i, t-2 k_{1}+2, j}, R O E_{i, t-2 k_{1}+3, j}, \cdots, R O E_{i, t-k_{1}+1, j}\right\}$ is the weighted return on assets of the representative company $j$ in industry $i$ at the time of $t-2 k_{1}+2 \sim t-k_{1}+1$; $N_{i}$ is the sample number of representative companies in industry $i$.

Then we calculate the annual cost of equity by CAPM, and to remove the noise information of CAPM parameters, we use the MA to correct. The cost of equity of industry $i$ in the $t$-th year is defined as

$$
\begin{aligned}
& R e_{i, t}=R f_{t}+\beta_{i, t} \times\left(R m_{i, t}-R f_{t}\right) \\
& =\frac{1}{k_{1}} \times\left\{\sum_{\lambda=t-k_{1}+1}^{t} T D R_{\lambda}+\beta_{i, t} \times\left(\frac{1}{N_{i}} \times \sum_{\lambda=t-k_{1}+1}^{t} \sum_{j=1}^{N_{i}} R O E_{i, \lambda, j}-\sum_{\lambda=t-k_{1}+1}^{t} T D R_{\lambda}\right)\right\}
\end{aligned}
$$

where $R f_{t}=\frac{\sum_{\lambda=t-k_{1}+1}^{t} T D R_{\lambda}}{k_{1}}$ is the risk-free rate of the $t-$ th year and can use deposit rate as a proxy for the riskfree because the deposit rate than government bond rate can better reflect the market supply-demand and investment condition in China, $T D R_{t-k_{1}+1}$ is the People's Bank of China (PBOC) three-year deposit interest rate in the $t-k_{1}+1-$ th year; $R m_{i, t}=\frac{\sum_{\lambda=t-k_{1}+1}^{t} \sum_{j=1}^{N_{i}} R O E_{i, \lambda, j}}{k_{1} \times N_{i}}$ is the average risk-return rate of the industry $i$ in the $t$-th year.

Capital structure is an influential factor for risk and rate of return in investment, which can use the proportion of debt and equity as the proxies. Because of the WACC call for a balanced capital structure [28], we use MA to correct the proportion of debt and the proportion of equity at the industry level and to slow down the fluctuations caused by the noise information of capital structure of enterprises. The proportion of debt can be obtained by the asset-liability ratios of representative companies defined as

$I d_{i, t}=\frac{1}{k_{1} \times N_{i}} \sum_{\lambda=t-k_{1}+1}^{t} \sum_{j=1}^{N_{i}} D A R_{i, \lambda, j}$,

where $D A R_{i, t-k_{1}+1, j}$ is the asset-liability ratio of the representative company $j$ in industry $i$ in the $t$-th year. Therefore, the proportion of equity is

$I e_{i, t}=1-I d_{i, t}$. 
The WACC as a proxy of discount rate consists partly of the cost of equity, which can be calculated by CAPM method, and partly of the cost of debt. Based on the formulations and text WACC [14,17], the formula of WACC can be represented as follows:

$w_{i, t}=R e_{i, t} \times I e_{i, t}+I d_{i, t} \times R d_{t} \times(1-T A X)$,

where $R d_{t}=\frac{\sum_{\lambda=t-k_{1}+1}^{t} L I R_{\lambda}}{k_{1}}$ is the cost of debt of the $t$-th year, $L I R_{t-k_{1}+1}$ is the loan interest rate of over five years in the $t-k_{1}+1$-th year; TAX is the income tax rate of the electrical power industry projects in China, taking 25\% in accordance with the Enterprise Income Tax Law of the People's Republic of China.

Based on the above formulations, the discount rate of industry $i$ in the $t+L-$ th year is defined as

$W_{i, t+L}=w_{i, t}+\frac{k_{1}-1}{k_{2}-1}\left(w_{i, t}-\underline{w}_{i, t}\right)+\frac{2 L}{k_{2}-1}\left(w_{i, t}-\underline{w}_{i, t}\right)$,

where $\underline{w}_{i, t}=\frac{1}{k_{2}} \sum_{\lambda=t-k_{2}+1}^{t} w_{i, t-k_{2}+1}$ is the MA value of $w_{i, t} ; k_{2}$ the second step size of the MA; $L$ is the forecast step size.

The core of the MA method lies in the choice of the size, which directly affects the validity of the result [29]. Because the MA-CAPM-WACC method is built upon the MA model, the choice of step size directly affects the validity of forecast for the MA-CAPM-WACC method. So, we check the accuracy of the forecast result of the MA-CAPM-WACC method. MSE test is a commonly used method for MA method, with smaller MSE values indicating a more reasonable selected step size, which is generally less than $5 \%$. The MSE value of industry $i$ is

$M S E_{i}=\frac{1}{n-k_{1}-k_{2}+1} \sum_{t=k_{1}+k_{2}}^{n}\left(w_{i, t}-W_{i, t}\right)^{2}$,

where $n$ is the calculated interval of the discount rate.

\subsection{Data Source}

The financing structure of a typical new energy power project combines non-traded equity investment with bank debt. Because the financing models used by companies are confidential [30], and the financial details in many implemented projects remain private [31], suitable data are hardly available to researchers [11]. So, based on the availability and openness of the data, we use the benchmark interest rate issued by the PBOC (http://www.pbc.gov.cn/) and listed company financial indicators issued by the Wind Economic Database as data sources.

(1) Two parameters, the central PBOC's three-year fixed deposit interest rate and over five years loan interest rate (2010-2019), are selected as the basis for the calculation of risk-free rate and cost of debt.

(2) Based on the intelligent filter of Wind Economic Database, we determine that there are 134 companies listed in Shenzhen Stock Exchange and Shanghai Stock Exchange whose main businesses are hydropower, nuclear power, wind power, and photovoltaic power. More specifically, 22, 29, 29, and 54 listed companies in the hydropower industry, nuclear power industry, wind power industry, and photovoltaic power industry were selected, respectively (Table 1). The data of the weighted return on assets (2006-2019) and the asset-liability ratios (2010-2019) are used in this paper. In addition, to ensure the scientific and reasonable data, we check each piece of data to see whether it is reliable and to screen out the negative weighted return on assets of enterprises. 
Table 1: Research samples of listed companies

\begin{tabular}{|c|c|c|c|c|c|c|c|}
\hline Industry & Stock code & Industry & Stock code & Industry & Stock code & Industry & Stock code \\
\hline $1-a$ & 600900.SH & $35-b$ & 002130.SZ & $69-c$ & 300772.SZ & $103-d$ & 601222.SH \\
\hline $2-a$ & 600025.SH & $36-b$ & 000875.SZ & $70-c$ & 603063.SH & $104-d$ & 600151.SH \\
\hline $3-a$ & 600886.SH & $37-b$ & 002318.SZ & 71-c & 600163.SH & $105-d$ & 601908.SH \\
\hline 4-a & 600674.SH & $38-b$ & 002756.SZ & $72-c$ & 600290.SH & $106-d$ & 002617.SZ \\
\hline $5-a$ & 600236.SH & $39-b$ & 000777.SZ & $73-c$ & 300443.SZ & $107-d$ & 300751.SZ \\
\hline $6-a$ & 000883.SZ & $40-b$ & 603333.SH & 74-c & 601218.SH & $108-d$ & 601137.SH \\
\hline $7-a$ & 600116.SH & 41-b & 000922.SZ & $75-c$ & 300129.SZ & $109-d$ & 002309.SZ \\
\hline $8-\mathrm{a}$ & 600131.SH & $42-b$ & 002167.SZ & $76-c$ & 600192.SH & $110-d$ & 603105.SH \\
\hline $9-\mathrm{a}$ & 600868.SH & $43-b$ & 002011.SZ & $77-c$ & 300569.SZ & $111-d$ & 002256.SZ \\
\hline $10-\mathrm{a}$ & 000791.SZ & $44-b$ & 603308.SH & $78-\mathrm{c}$ & 300690.SZ & $112-d$ & 002518.SZ \\
\hline $11-\mathrm{a}$ & 600452.SH & $45-\mathrm{b}$ & 002255.SZ & $79-c$ & 300040.SZ & $113-d$ & 000862.SZ \\
\hline $12-\mathrm{a}$ & 000601.SZ & $46-b$ & 002438.SZ & $80-c$ & 300169.SZ & $114-d$ & 002335.SZ \\
\hline $13-\mathrm{a}$ & 600979.SH & $47-b$ & 002149.SZ & $81-d$ & 601012.SH & $115-d$ & 600537.SH \\
\hline $14-\mathrm{a}$ & 002039.SZ & $48-\mathrm{b}$ & 300004.SZ & $82-d$ & 601727.SH & $116-d$ & 002459.SZ \\
\hline $15-\mathrm{a}$ & 600310.SH & $49-b$ & 600202.SH & $83-d$ & 600438.SH & $117-d$ & 300317.SZ \\
\hline $16-\mathrm{a}$ & 600995.SH & $50-\mathrm{b}$ & 300092.SZ & $84-d$ & 601877.SH & $118-d$ & 002516.SZ \\
\hline $17-\mathrm{a}$ & 000993.SZ & $51-b$ & 300489.SZ & $85-d$ & 002506.SZ & 119-d & 600207.SH \\
\hline $18-\mathrm{a}$ & 000722.SZ & $52-\mathrm{c}$ & 002202.SZ & 86-d & 600522.SH & $120-d$ & 002218.SZ \\
\hline $19-\mathrm{a}$ & 600644.SH & $53-\mathrm{c}$ & 600875.SH & $87-d$ & 002129.SZ & $121-d$ & 300393.SZ \\
\hline $20-\mathrm{a}$ & 600101.SH & $54-c$ & 601615.SH & $88-d$ & 600089.SH & $122-d$ & 300763.SZ \\
\hline $21-a$ & 600969.SH & $55-\mathrm{c}$ & 002080.SZ & 89-d & 603806.SH & $123-d$ & 300111.SZ \\
\hline $22-\mathrm{a}$ & 600505.SH & $56-\mathrm{c}$ & 600483.SH & $90-d$ & 601865.SH & $124-d$ & 600135.SH \\
\hline $23-b$ & 601985.SH & $57-c$ & 601016.SH & 91-d & 300316.SZ & $125-d$ & 002006.SZ \\
\hline $24-b$ & 601727.SH & $58-\mathrm{c}$ & 002531.SZ & $92-d$ & 300274.SZ & $126-d$ & 300080.SZ \\
\hline $25-b$ & 600875.SH & $59-c$ & 601619.SH & $93-d$ & 002056.SZ & $127-d$ & 300391.SZ \\
\hline $26-b$ & 600021.SH & $60-\mathrm{c}$ & 603693.SH & 94-d & 000012.SZ & $128-d$ & 603507.SH \\
\hline $27-b$ & 601106.SH & 61-c & 002204.SZ & $95-d$ & 000040.SZ & $129-d$ & 300655.SZ \\
\hline $28-b$ & 601611.SH & $62-c$ & 600458.SH & 96-d & 000591.SZ & $130-d$ & 002623.SZ \\
\hline $29-b$ & 002266.SZ & $63-c$ & 000958.SZ & $97-d$ & 002665.SZ & $131-d$ & 603628.SH \\
\hline $30-b$ & 000969.SZ & $64-c$ & 300185.SZ & 98-d & 600770.SH & $132-d$ & 002660.SZ \\
\hline $31-b$ & 603699.SH & $65-c$ & 600416.SH & 99-d & 601619.SH & $133-d$ & 300554.SZ \\
\hline $32-b$ & 603169.SH & $66-c$ & 000791.SZ & $100-d$ & 300118.SZ & $134-d$ & 300029.SZ \\
\hline $33-b$ & 002366.SZ & $67-c$ & 000836.SZ & $101-d$ & 300724.SZ & & \\
\hline $34-b$ & 000881.SZ & $68-\mathrm{c}$ & $000862 . \mathrm{SZ}$ & $102-d$ & 002610.SZ & & \\
\hline
\end{tabular}

Note: -a presents that the firms belong to the hydropower industry, -b presents that the firms belong to the nuclear power, -c presents that the firms belong to the wind power industry, -d presents that the firms belong to the photovoltaic power industry. 


\section{Results and Discussion}

\subsection{Beta and Cost of Equity}

Beta and cost of equity are also very important parameters of investment decisions and risk evaluation for investors when it comes to a new energy power project. The beta and cost of equity of China's new energy power industries are shown in Table 2. From the perspective of risk analysis, the beta change of the hydropower industry is the most stable, followed by the nuclear power industry, while the betas in wind power industry and photovoltaic power industry fluctuate, especially in the photovoltaic industry from 2014 to 2019. During the period, because of a highly mature market, policy system, and technology, the beta of the hydropower industry frequently fluctuates under the influence of reform, but over a small range. The beta of the nuclear power industry is relatively stable because the enterprises in the industry are mainly state-owned enterprises, but there is a large range for change. This is because nuclear power projects have high cost, high safety standard, and wide and deep accident scope characteristics, which make betas in the nuclear power industry sensitive to external factors. Because of the late start of the market and power policy adjustment, the betas in the wind power industry and photovoltaic power industry fluctuate greatly. The beta changes of the four industries reflect the development of China's electricity market. Additionally, similar trends over time are reflected in the cost of capital analysis of China's new energy power industries. From 2014 to 2019, the cost of equity in the hydropower industry was between $10.70 \%$, and $11.54 \%$, which is less volatile and more stable than other power industries. The cost of equity in the nuclear power industry is between $6.55 \%$ and $9.23 \%$, showing an overall reduction. The cost of equity fluctuations in the wind power industry and the photovoltaic power industry are prevalent, especially in the photovoltaic power industry, which include $[6.22 \%, 7.96 \%]$ and $[11.32 \%$, $13.36 \%$ ]. In 2019, the photovoltaic power industry had the highest cost of equity, followed by hydropower industry, wind power industry, and nuclear power industry. The cost of equity of the renewable energy power industry is higher than the non-renewable energy power industry.

Table 2: The beta and cost of equity in China's new energy power industry during 2014-2019

\begin{tabular}{llllll}
\hline Year & Parameter & Hydropower & Nuclear power & Wind power & Photovoltaic power \\
\hline 2014 & Beta & 1.29 & 1.03 & 1.04 & 1.24 \\
& Cost of equity & $11.42 \%$ & $9.23 \%$ & $7.95 \%$ & $11.32 \%$ \\
2015 & Beta & 1.3 & 0.77 & 1.1 & 1.49 \\
& Cost of equity & $11.49 \%$ & $7.80 \%$ & $7.21 \%$ & $13.36 \%$ \\
2016 & Beta & 1.22 & 0.75 & 0.85 & 1.31 \\
& Cost of equity & $11.54 \%$ & $7.14 \%$ & $6.36 \%$ & $12.41 \%$ \\
2017 & Beta & 1.17 & 0.8 & 0.82 & 1.17 \\
& Cost of equity & $11.54 \%$ & $7.06 \%$ & $6.22 \%$ & $12.37 \%$ \\
2018 & Beta & 1.11 & 0.83 & 1.08 & 1.21 \\
& Cost of equity & $11.32 \%$ & $6.55 \%$ & $7.26 \%$ & $12.69 \%$ \\
& Beta & 1.12 & 1 & 1.24 & 1.26 \\
& Cost of equity & $10.70 \%$ & $6.90 \%$ & $7.96 \%$ & $13.29 \%$ \\
\hline
\end{tabular}




\subsection{Discount Rate of China's New Energy Power Industry}

In 2019, the discount rates of China's hydropower, nuclear power, wind power, and photovoltaic power industries were $7.17 \%, 5.26 \%, 5.72 \%$, and $8.66 \%$, respectively. The photovoltaic power industry had the highest discount rate, followed by hydropower industry, wind power industry, and nuclear power industry. Compared with the development trend of cost of equity of China's new energy power industries in Table 2, we can see that the development trend of discount rate in Table 3 is similar to the development trend of cost of equity in China's new energy power industries from 2014 to 2019. This also indicates that the cost of equity plays a substantial role in the discount rate. From 2014 to 2019, the discount rates of the four industries all show a fluctuating state. The discount rate changes of the hydropower industry were $7.56 \%$, with a maximum range of $0.39 \%$. The discount rates of the nuclear power industry fluctuated at a level of $5.83 \%$. The discount rates of the wind power industry fluctuated around $5.60 \%$. Discount rates of the photovoltaic power fluctuate most among the four industries, with around $8.64 \%$. This phenomenon indicates that the external environment of the industry changed to a certain extent. One main reason is that policy promulgation, revision, and abolition frequently occur in China's new energy power industries for the period of 2014-2019. For example, the National Energy Administration announced the revision and abolition of 102 documents involving the power industry in 2016 No. 5, and the National Energy Administration's 2019 No. 7 document revised and repealed 182 documents related to the power industry. This kind of sudden change causes serious outliers in the annual estimate of discount rate, shown as cutting-edge irregular fluctuations in the time series. According to the changes of discount rates in the four industries, it can be seen that the discount rates in the wind power industry and the photovoltaic power industry have changed more substantially from 2014 to 2019 than in the hydropower and nuclear power industries. The main reason is that the China energy power adjustment focuses on the wind power and photovoltaic power industries, such as the National Energy Administration's No. 7 document of 2019, which abolished seven wind power regulatory documents and one photovoltaic policy, retained 19 photovoltaic policies, and revised one photovoltaic policy, involving a total of 21 photovoltaic policies.

Table 3: Discount rate of China's new energy power industry

\begin{tabular}{lllllll}
\hline Industry category & $2014(\%)$ & $2015(\%)$ & $2016(\%)$ & $2017(\%)$ & $2018(\%)$ & $2019(\%)$ \\
\hline Hydropower & 7.66 & 7.72 & 7.67 & 7.63 & 7.51 & 7.17 \\
Nuclear power & 6.95 & 6.19 & 5.76 & 5.59 & 5.21 & 5.26 \\
Wind power & 6.18 & 5.80 & 5.30 & 5.12 & 5.48 & 5.72 \\
Photovoltaic power & 8.34 & 9.32 & 8.63 & 8.43 & 8.48 & 8.66 \\
\hline
\end{tabular}

Specifically, the discount rate values in the hydropower industry showed an initial increasing trend and then a decreasing trend during this period. This may be related to the excess capacity of hydropower. Under the influence of multiple factors such as market, policy, and electricity price, the investment enthusiasm of hydropower development enterprises is seriously affected, which results in high investment risk of investors, high expected rate of return, and high capital cost of financing. In this case, China decided to carry out in an all-round way of China's electric power reform since 2016. A series of favorable policies have been issued, such as the Implementation Plan for Solving the Problem of Abandoning Water, Wind and Light, and on Promoting the Homogeneity of Hydropower Consumption in Southwest China, which provide important 
policy support for the absorption of hydropower. The development of discount rate in the nuclear power industry from 2014 to 2019 is relatively stable, showing a general downward trend. On the one hand, because of the uniqueness of nuclear energy, the main investors are state-owned enterprises, which also is mentioned earlier in Section 3.1. On the other hand, with the rapid development of the nuclear power market, the market scale of the nuclear power industry is gradually expanding, and the technology and manufacturing is increasing in maturity. The discount rate of the wind power industry shows an initial decreasing trend, followed by an increasing trend. The main reason is that the wind power industry is originally state-supported, which allowed for rapid development with market development and policy support. Thus, the discount rate of wind power investment projects shows a downward trend for the period of 2014-2017. However, because of rapid development of the wind power industry, the wind power market has become chaotic, and the phenomenon of wind abandonment is serious. The state has begun to implement a subsidy regression to regulate the market and to order and improve the development quality of the wind power industry. This change has dampened investor enthusiasm and made investments more cautious in the wind power industry. Therefore, the discount rate of wind power investment projects shows a rising trend for the period of 2017-2019. The development situation of the photovoltaic power industry is similar to the wind power industry development because it was also originally a state supported industry. The discount rate in the photovoltaic power industry is different from the overall declining trend of the discount rate in the wind power industry because it has an overall increasing trend. The discount rate in the photovoltaic power industry fluctuates more than the discount rate in the wind power industry. Two aspects may explain this difference: one is that the China photovoltaic power industry starts late and originally belongs to the state supportive industries so that the relevant policies change frequently, and the other is that the European and American countries take antidumping and countervailing measures for China photovoltaic power industry, which increases risks of the photovoltaic power industry. These are also important reasons why the photovoltaic power industry discount rate is the highest among the four industries.

Noise information of historical data shows temporary variations and outliers in the annual estimates of discount rates. We compare the calculation results of MA-CAPM-WACC and the CAPM-WACC model (Fig. 3), in which CAPM-WACC method consists of unconditional CAPM and text WACC to further highlight the advantages of the proposed method. We also calculate the Analysis of Variance (ANOVA) of China's new energy power industries by MA-CAPM-WACC and CAPM-WACC, shown in Table 4. The ANOVA of discount rates by MA-CAPM-WACC model was smaller than by CAPM-WACC, and all ANOVA values were $0.00 \%$, which verifies that the MA-CAPM-WACC can reduce the noise information and enhance the stabilization. Meanwhile, it can be intuitively seen from curve shapes of discount rates in Fig. 3 that the discount rates of the hydropower, nuclear power, wind power, and photovoltaic power industries estimated based on the CAPM-WACC model fluctuated during the research period, especially the discount rates of the photovoltaic power industry. Through the correction by MA-CAPM-WACC, the discount rates are stabilized. The proposed method, MA-CAPM-WACC, can effectively address the shortterm irregular fluctuations in the discount rate and reduce or eliminate the influence of irregular outliers on model calculations, which can be appropriate for discount rates of China's new energy power industry in the context of the great reform. Relevant results of China's new energy power industry can provide more valuable information for enterprises in aspects of investment decisions, project financing, and risk analysis of new energy projects, and avoid errors or information distortion caused by short-term uncertainties. 


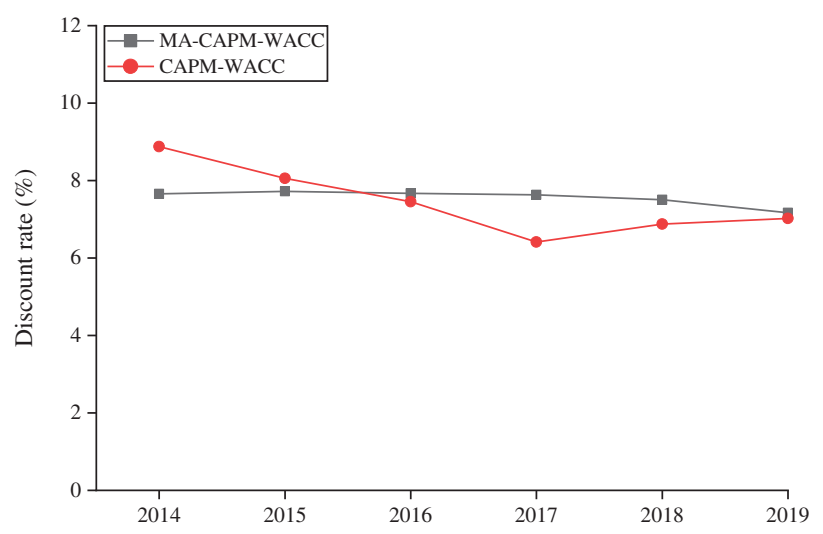

(a)

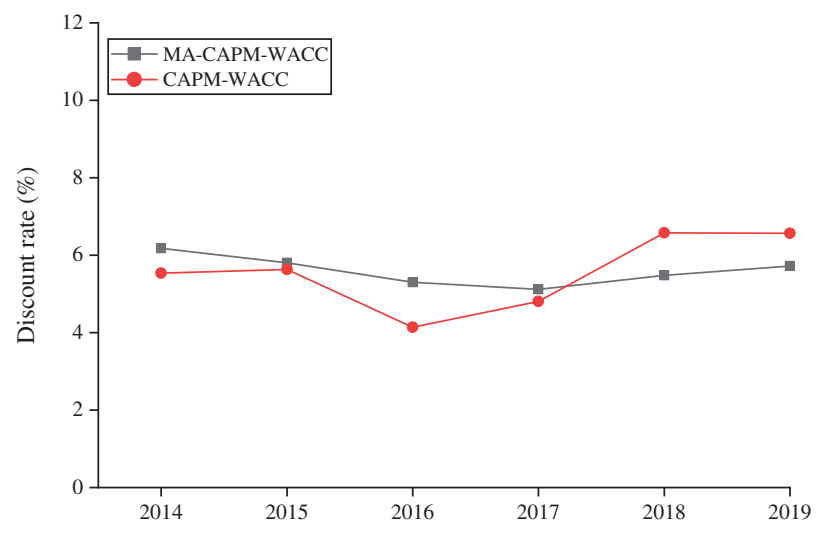

(c)

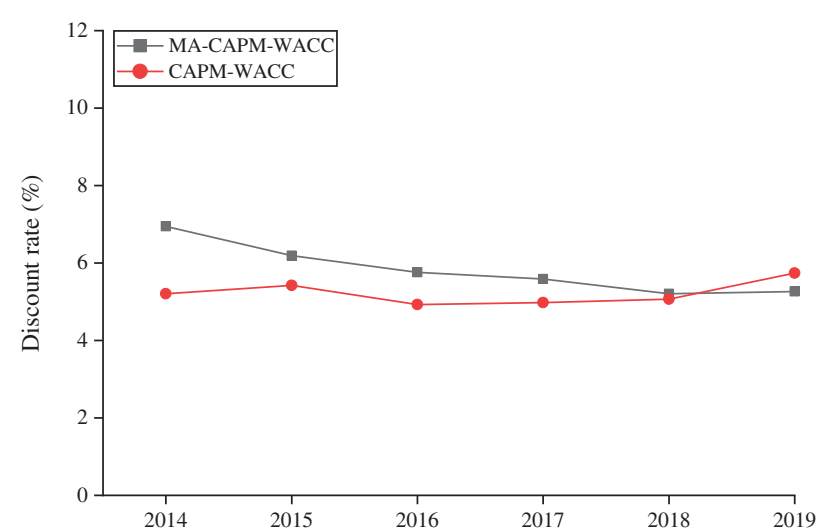

(b)

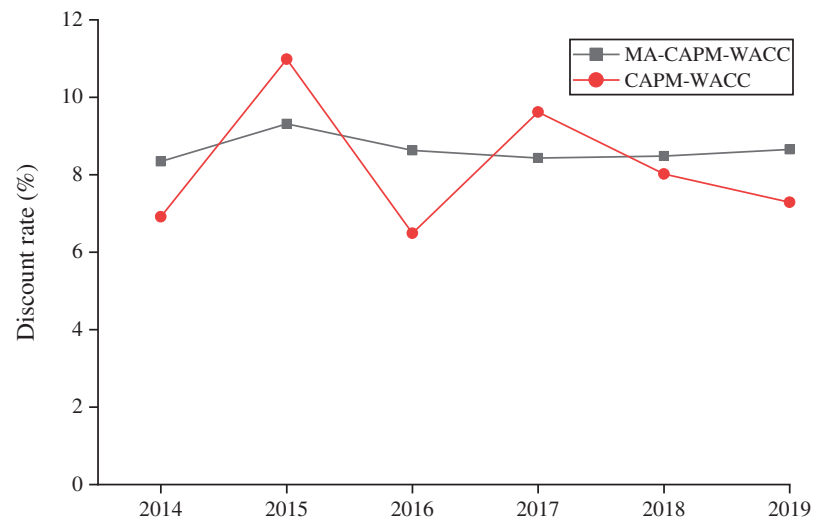

(d)

Figure 3: Discount rate of China's new energy power industry using different evaluation methods during 2014-2019. (a) hydropower industry, (b) nuclear power industry, (c) wind power industry, (d) photovoltaic power industry

Table 4: The NOVA of China new energy power industry using different evaluation methods

\begin{tabular}{lllll}
\hline Evaluation method & Hydropower & Nuclear power & Wind power & Photovoltaic power \\
\hline MA-CAPM-WACC & 0 & 0 & 0 & 0 \\
CAPM-WACC & $0.00 \%$ & 0 & $0.01 \%$ & $0.03 \%$ \\
\hline
\end{tabular}

\subsection{MSE Test and Forecast Analysis of China's New Energy Power Industry}

We regard the calculated interval of beta as the first step size, usually $k_{1}=5$ to ensure the rationality and comparability of all parameters in terms of determination and selection and calculation results. According to the relationship of the first step size and second step size, the second step size is $k_{2}=3$. We calculate the MSE value in China's new energy power industry using Eq. (7) with the results shown in Table 5, indicating that the MSE values are less than $0.05 \%$. The selection of MA step size is reasonable, and the forecast result is accurate. We use Eq. (6) to forecast discount rates for China's hydropower, nuclear power, wind power, and photovoltaic power industries in 2020, 2025, and 2030, shown in Table 5 . During the forecast period, we expect the highest discount rates for photovoltaic power, followed by the wind power, hydropower, and nuclear power industries. 
Table 5: MSE and discount rate forecast of China's new energy power industry

\begin{tabular}{lllll}
\hline Industry & Hydropower (\%) & Nuclear power (\%) & Wind power (\%) & Photovoltaic power (\%) \\
\hline MSE & 0.00 & 0.01 & 0.01 & 0.00 \\
2020 & 6.37 & 5.00 & 6.57 & 9.05 \\
2025 & 5.05 & 4.55 & 7.97 & 9.72 \\
2035 & 3.99 & 4.19 & 9.10 & 10.25 \\
\hline
\end{tabular}

We use 2019 as the evaluation base period to forecast the discount rates of China's hydropower, nuclear power, wind power, and photovoltaic power industries under the different capital structures, in 2020, 2025, and 2030 (Fig. 4). Under the different scenario simulations, higher proportions of equity result in higher discount rates [32]. The discount rates in the photovoltaic power industry are more affected by the capital structure than the other three industries. The discount rate forecast values of China's renewable energy power industries are more affected by the capital structure than non-renewable energy power industries. Discount rates in the wind power industry and photovoltaic power industry are consistent under different capital structures over the course of time. This is mainly because their development processes are similar. Both of them were supported after the promulgation of the Renewable Energy Law in 2005. As the supporting industries in the same period, China generally issued relevant policies, laws, and regulations on wind power and photovoltaic power in the same document, such as the Notice on Matters Related to the Construction of Wind Power and Photovoltaic Power Generation Projects in 2019.

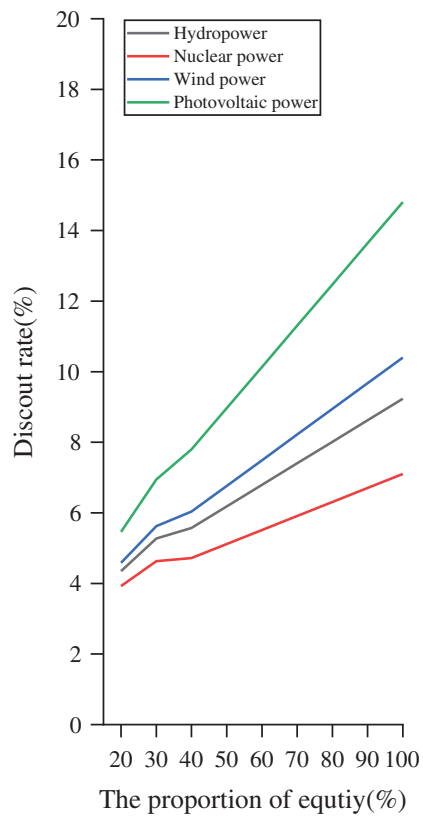

(a)

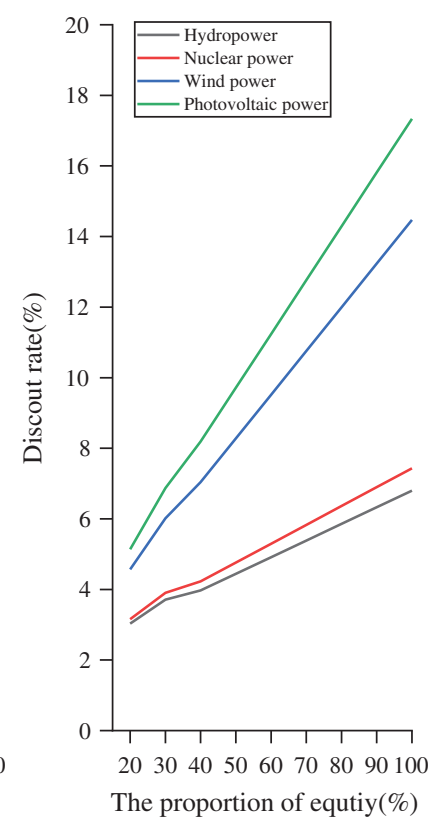

(b)

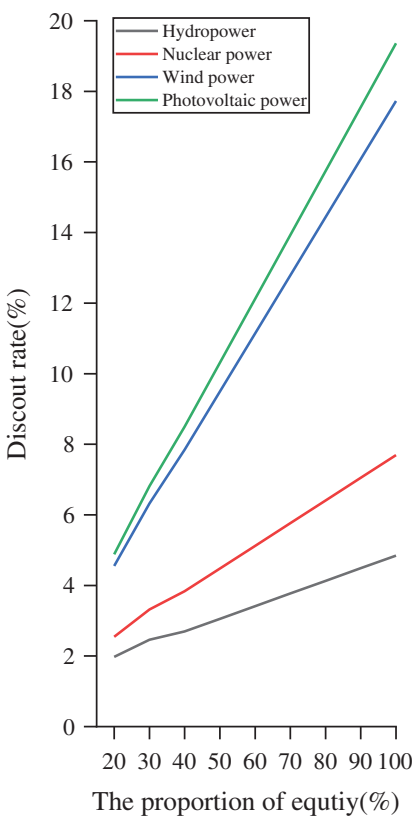

(c)

Figure 4: The forecast values of discount rates in China's new energy industry under the different capital structures. (a) in 2020, (b) in 2025, (c) in 2030

The sensitivity of the different industries to capital structure is different. For example, in the hydropower industry, the sensitivity of capital structure with the increase of time is relatively stable, mainly because the development of the hydropower industry, market, finance, and system is relatively perfect. Project financing 
is not confined to the support of its own funds but can obtain financing through multiple channels. However, the sensitivity of the nuclear power industry to the capital structure depends on the capital structure. Under the context that the proportion of equity is below $[70 \%, 80 \%]$, the sensitivity of the nuclear power industry to the capital structure will gradually decrease over time, but under the context that the proportion of equity is over $[70 \%, 80 \%]$, the sensitivity of the nuclear power industry to the capital structure will gradually increase over time. This indicates that nuclear power investment risks are low when the proportion of equity of the company is lower than $[70 \%, 80 \%]$, while investment is not recommended when the proportion of equity is higher than $[70 \%, 80 \%]$. Similar to the situation of the nuclear power industry, the sensitivity of the photovoltaic power industry to the capital structure will decrease with time when the proportion of equity is lower than [30\%, 40\%]. When the proportion of equity exceeds $[30 \%, 40 \%]$, the sensitivity to the capital structure will increase with time. Compared with the nuclear power industry, the turning point of the sensitivity of the photovoltaic power industry to the capital structure is lower, mainly because companies are mostly state-owned enterprises in the nuclear power industry. However, the photovoltaic power industry is different. The sensitivity of the wind power industry to the capital structure with the increase of the proportion of equity gradually increases with the increase of time. Combined with the above analysis, in the future, the government should strengthen financial market supervision, improve the modern financial supervision system, strengthen institutional construction, improve the transparency and rule of law of financial supervision, and promote the market-oriented development of the new energy power industry, especially in the wind power industry and photovoltaic power industry.

\section{Conclusions and Policy Implications}

In this paper, we study annual discount rates of China's hydropower, nuclear power, wind power, and photovoltaic power industries for the period of 2014-2019, by using a proposed method that uses MA to correct parameters of CAPM and WACC and avoid the noise information effect of historical data. The main results are summarized as follows:

(1) In 2019, the discount rates of China's hydropower, nuclear power, wind power, and photovoltaic power industries are $7.17 \%, 5.26 \%, 5.72 \%$, and $8.66 \%$, respectively. The photovoltaic power industry has the highest discount rate, followed by the hydropower, wind power, and nuclear power industries. During the period of 2014-2019, the discount rate of the hydropower industry is stable, fluctuating at a level of $7.56 \%$ as a whole. The discount rate of the nuclear power industry during the research period is stable, overall showing a decreasing trend, and fluctuates at a level of $5.83 \%$. The discount rates of the wind power industry initially decrease but then increase, and the average discount rate is the smallest among four industries at $5.60 \%$. The discount rate of the photovoltaic power industry fluctuates most among the four industries, at $8.64 \%$. Also, beta and the cost of capital are substantial parameters reflecting the discount rate and have a similar pattern for temporal trends in China's new energy power industries. The parameters of the hydropower industry and nuclear power industry have relatively stable trends, while the parameters of the wind power industry and the photovoltaic power industry have small fluctuations in China from 2014 to 2019.

(2) Forecasting forward from the 2019 base period, the hydropower, nuclear power, wind power, and photovoltaic power industries are $6.37 \%, 5.00 \%, 6.57 \%$, and $9.05 \%$, respectively, in 2020 . Under different capital structures, the discount rate forecasts in 2020 are [4.35\%, 9.24\%], [3.92\%, 7.10\%], $[4.58 \%, 10.40 \%]$, and $[5.46 \%, 14.81 \%]$ for the respective industries. The discount rates in the photovoltaic industry are more affected by the capital structure than the other three industries, followed by the wind power, hydropower, and nuclear power industries. Combining the time dimension with the capital structure dimension, the sensitivity of capital structure is relatively stable in the hydropower industry with the increase of time. The sensitivity of the wind power industry to the capital structure with the increase of the proportion of equity gradually increases with the increase of time. The sensitivity of the nuclear power industry and photovoltaic power industry to the capital structure with the increase of 
time depends on the capital structure. In the nuclear power industry, if the proportion of capital is less than $[70 \%, 80 \%]$, the sensitivity to the capital structure will gradually decrease over time; if it is above this range, the sensitivity to the capital structure decreases. Similarly, in the photovoltaic power industry, if the proportion of capital is higher than [30\%, 40\%], the sensitivity to capital structure will go up over time; if it is lower than $[30 \%, 40 \%]$, the sensitivity to the capital structure will gradually decrease over time.

Based on the above analysis, we put forward some policy implications to accelerate the marketization process of China's new energy power industry.

(1) China should strengthen the collection and collation of new energy power industry resource data to establish a new energy power industry database and provide a data guarantee for the construction of new energy electric fields. At present, since the discount rate parameter involves the enterprise information, a lot of financial information is confidential, which makes it difficult to obtain the research data. Therefore, the Chinese government should take the lead to strengthen the collection and collation of new energy investment data and form a relatively complete resource database, so as to promote the development of China's new energy power industry.

(2) Steadily promote the implementation of policies. We need to start from the aspects of market operation model, trading mechanism, and implementation path, and give full play to the medium- and long-term role of policy to better complete the transformation and target reform. In particular, the wind power industry and photovoltaic power industry are in periods of subsidy retreat, so it is necessary to give full play to the policy advantages, and properly and accurately implement the feed-in tariff policy.

Funding Statement: The authors received no specific funding for this study.

Conflicts of Interest: The authors declare that they have no conflicts of interest to report regarding the present study.

\section{References}

1. Steffen, B. (2020). Estimating the cost of capital for renewable energy projects. Energy Economics, 88, 104783. DOI 10.1016/j.eneco.2020.104783.

2. Bachner, G., Mayer, J., Steininger, K. W. (2019). Costs or benefits? Assessing the economy-wide effects of the electricity sector's low carbon transition-The role of capital costs, divergent risk perceptions and premiums. Energy Strategy Reviews, 26, 100373. DOI 10.1016/j.esr.2019.100373.

3. Sweerts, B., Longa, F. D., Zwaan, B. V. D. (2019). Financial de-risking to unlock Africa's renewable energy potential. Renewable and Sustainable Energy Reviews, 102(80), 75-82. DOI 10.1016/j.rser.2018.11.039.

4. Luo, L. L., Chen, S., Zou, Z. R. (2020). Determining the generalized discount rate for risky projects. Environmental \& Resource Economics, 77(1), 143-158. DOI 10.1007/s10640-020-00458-5.

5. Guthrie, G. (2012). Regulated prices and real option. Telecommunications Policy, 36(8), 650-663. DOI 10.1016/j. telpol.2012.04.013.

6. Rady, A., Meshreki, H., Ismail, A., Nunez, L. (2019). Variations in valuation methodologies and the cost of capital: Evidence from MENA countries. Emerging Markets Finance and Trade, 55(9), 2106-2123. DOI 10.1080/ 1540496X.2018.1533462.

7. Leisen, R., Steffen, B., Weber, C. (2019). Regulatory risk and the resilience of new sustainable business models in the energy sector. Journal of Cleaner Production, 219, 865-878. DOI 10.1016/j.jclepro.2019.01.330.

8. Xu, Z. X. (2019). Economic policy uncertainty, cost of capital, and corporate innovation. Journal of Banking \& Finance, 111, 105698. DOI 10.1016/j.jbankfin.2019.105698.

9. Leskinen, N., Vimpari, J., Junnila, S. (2019). Using real estate market fundamentals to determine the correct discount rate for decentralised energy investments. Sustainable Cities and Society, 53, 101953. DOI 10.1016/j.scs.2019.101953.

10. Mazzucato, M., Semieniuk, G. (2018). Financing renewable energy: Who is financing what and why it matters. Technological Forecasting and Social Change, 127(1), 8-22. DOI 10.1016/j.techfore.2017.05.021. 
11. Egli, F., Steffen, B., Schmidt, T. S. (2018). A dynamic analysis of financing conditions for renewable energy technologies. Nature Energy, 3(12), 1084-1092. DOI 10.1038/s41560-018-0277-y.

12. Egli, F. (2020). Renewable energy investment risk: An investigation of changes over time and the underlying drivers. Energy Policy, 140(1), 111428. DOI 10.1016/j.enpol.2020.111428.

13. Inmaculada, G., Ana, B. (2020). Analyzing profitability and discount rates for solar PV plants. A Spanish case. Sustainability, 12(8), 3157. DOI 10.3390/su12083157.

14. Angelopoulos, D., Brueckmann, R., Jirous, F., Konstantinaviciute, I. (2016). Risks and cost of capital for onshore wind energy investments in EU countries. Energy \& Environment, 27(1), 82-104. DOI 10.1177/0958305X16638573.

15. Markauskas, M., Saboniene, A. (2020). Evaluation of capital cost: Long run evidence from manufacturing sector. Engineering Economics, 31(2), 169-177. DOI 10.5755/j01.ee.31.2.21439.

16. Vartiainen, E., Masson, G., Breyer, C., Moser, D. (2019). Impact of weighted average cost of capital, capital expenditure, and other parameters on future utility-scale PV levelised cost of electricity. Progress in Photovoltaics, 28(6), 439-453. DOI 10.1002/pip.3189.

17. Miles, J. A., Ezzell, J. R. (1980). The weighted average cost of capital, perfect capital markets, and project life: A clarification. Journal of Financial and Quantitative Analysis, 15(3), 719-730. DOI 10.2307/2330405.

18. Frank, M. Z., Shen, T. (2015). Investment and the weighted average cost of capital. Journal of Financial Economic, 119(2), 300-315. DOI 10.1016/j.jfineco.2015.09.001.

19. Angelopoulos, D., Doukas, H., Psarras, J., Stamtsis, G. (2017). Risk-based analysis and policy implications for renewable energy investments in Greece. Energy Policy, 105(11), 512-523. DOI 10.1016/j.enpol.2017.02.048.

20. Vergara, C., Rojas, J. P. S., Alfaro, M., Riveros, N. (2018). Cost of capital estimation for highway concessionaires in Chile. Journal of Advanced Transportation, 3(3), 1-9. DOI 10.1155/2018/2153536.

21. Elton, E. J. (1999). Presidential address: Expected return, realized return, and asset pricing tests. Journal of Finance, 54(4), 1199-1220. DOI 10.1111/0022-1082.00144.

22. Hou, K. W., Dijk, M. A. V., Zhang, Y. (2012). The implied cost of capital: A new approach. Journal of Accounting \& Economics, 53(3), 504-526. DOI 10.1016/j.jacceco.2011.12.001.

23. Nhleko, A. S., Musingwini, C. (2016). Estimating cost of equity in project discount rates using the capital asset pricing model and Gordon's wealth growth model. International Journal of Mining, 30(5), 390-404. DOI 10.1080/17480930.2015.1093675.

24. Chrysafis, K. A. (2012). Corporate investment appraisal with possibilistic CAPM. Mathematical \& Computer Modelling, 55(3-4), 1041-1050. DOI 10.1016/j.mcm.2011.09.029.

25. Akrami, S. A., El-Shafie, A., Naseri, M., Santos, C. A. G. (2014). Rainfall data analyzing using moving average (MA) model and wavelet multi-resolution intelligent model for noise evaluation to improve the forecasting accuracy. Neural Computing \& Applications, 25(7-8), 1853-1861. DOI 10.1007/s00521-014-1675-0.

26. Eraldo, B., Tomislav, G., Jurica, S. (2007). Analysis of economic characteristics of a tariff system for thermal energy activities. Energy Policy, 35(11), 5591-5600. DOI 10.1016/j.enpol.2007.05.027.

27. Giaccotto, C., Giambona, E., Zhao, Y. H. (2020). Short-term and long-term discount rates for real estate investment trusts. Journal of Real Estate Finance and Economics, 64(4), 535. DOI 10.1007/s11146-020-09750-z.

28. Block, S. (2011). Does the weighted average cost of capital describe the real-world approach to the discount rate? Engineering Economist, 56(2), 170-180. DOI 10.1080/0013791X.2011.573618.

29. Lee, Y., Brorsen, B. W. (2017). Permanent shocks and forecasting with moving averages. Applied Economics, 49(10-12), 1-13. DOI 10.1080/00036846.2016.1213368.

30. Dobrotkova, Z., Surana, K., Audinet, P. (2018). The price of solar energy: Comparing competitive auctions for utility-scale solar PV in developing countries. Energy Policy, 118, 133-148. DOI 10.1016/j.enpol.2018.03.036.

31. Steffen, B. (2018). The importance of project finance for renewable energy projects. Energy Economics, 69, 280294. DOI 10.1016/j.eneco.2017.11.006.

32. Ignacio, V. P., Joseph, T. (2009). Market value calculation and the solution of circularity between value and the weighted average cost of capital WACC. RAM. Revista de Administração Mackenzie, 10(6), 101-131. DOI 10.1590/S1678-69712009000600007. 